\title{
Inventory of fauna as a tool for sustainable use of economically important mammal species (on the example of the Tashkent region of Uzbekistan)
}

\author{
Roman Kashkarov*, Yuliya Mitropolskaya \\ ${ }^{1}$ Institute of Zoology, Academy of Science, 232B, Bogi Shamol Str., Tashkent 100053, Uzbekistan
}

\begin{abstract}
This paper describes the first experience for Uzbekistan in mammals' fauna inventory in the context of large administrative districts. Tashkent region was chosen as a model territory for researching - as an integral natural area with natural geographical boundaries. A revision of the composition and assessment of the fauna current conditions of economically significant mammals of this region was carried out. The primary limiting factors and threats to the existence of these species were analyzed. The permissible standards for the removal of economically significant mammalian species from the natural environment were determined, based on the data of the abundance and their habitats conditions. Standard approaches and methods for inventory have been developed: data collection and storage; working with sources of existing information; field research as the gaps closing basic method. Based on the results of the research, standard species profiles were prepared for 17 economically significant mammalian species, including data on distribution, landscape location, abundance, and permissible operational loads. A proposal to change the current conservation status of the Long-tailed Marmot, Corsac Fox and Steppe Polecat was justified. These species were previously considered as hunting objects, but now they have become rare. The impact of introduced and invasive species - Coypu, Muskrat, American Mink and Norway Rat on the native fauna was determined. The analysis of negative impacts on the species allowed to recommend a number of applied measures for the sustainable use of biological resources.
\end{abstract}

\section{Brief description of the scientific problem}

The conservation and sustainable use of the environment and biological resources during the period of intensive economic and social development of Uzbekistan is a vital task and one of the priorities of the state policy of Uzbekistan. The management of any resources is based on their reserves determination. In case of wildlife objects using, the inventory and assessment of the fauna current conditions is the basis, and the monitoring system is the tool for this [1].

Significant changes in the environmental conditions of the country take place as a result of intensive economic activity. This problem is particularly acute for the metropolitan area

\footnotetext{
*Corresponding author: roman.kashkarov@,iba.uz
} 
- the Tashkent region. The particularly serious changes have taken place in the fauna conditions of the Tashkent region over the last 10-15 years. Economically significant speciess were first of all affected by degradation and reduction of the habitats area and illegal hunting. This determined the objective need for inventory of the fauna of this group of animals.

Currently, the state planning and implementation of measures for the conservation, restoration and sustainable use of biodiversity in Uzbekistan has a clear administrative structure. However, the fauna inventory in the context of administrative regions in Uzbekistan was not carried out. Therefore, there are no up-to-date data on the abundance conditions of various vertebrate species by regions.

This research is the basis for developing the recommendations for the fauna inventory of other regions of the country, including economically significant species of mammals. Consolidation of all available information in a single format, supplementing it with up-todate data and filling of existing gaps makes it possible to identify possible ways of sustainable use of this important biological resource.

\subsection{Research area description}

Tashkent region is the administrative and socio-economic center of the Republic of Uzbekistan and is located in the north-east of the country. It is the only one of the regions that has natural geographical boundaries and is an integral natural area with the area of $15,250 \mathrm{~km} 2$. Its south-western part is represented by plain areas in the interstream of two large rivers - Chirchik and Akhangaran, which flow into the Syr Darya River. The northeastern part of the region includes the spurs of the Western Tien Shan mountain system Karzhantau, Ugam, Pskem, Maydantal, Talas, Kuramin and Chatkal ridges with extensive foothills - adyrs belt. A variety of natural landscapes - from river valleys and reservoirs to highlands and glaciers (Fig. 1) are presented here.

Large industrial enterprises operate in the region - Chirchik Integrated Chemical Plant, Angren Coal Plant, Akhangaran and Almalyk Cement Plants and the largest power plant Charvak HPP. Since 2017, work on the construction of one of the Pskem HPP, the largest hydro power plants in Central Asia, has begun in the Pskem river valley. Modern transportational routes, including Angren-Pap railway, have been built. Vast mountainous and even lands are used in agriculture for distant-pasture livestock breeding and crop production. In recent years, an intense population growth due to the influx from neighboring regions are observed here. Recreation has been actively developed - the number of tourists visiting natural areas is growing, old public recreation areas are being reconstructed and new ones are being created.

\section{Material and methods}

The inventory of terrestrial vertebrate fauna in the context of administrative regions was carried out for the first time in Uzbekistan in 2018-2020 within the framework of the applied project of the Institute of Zoology of the Academy of Sciences of the Republic of Uzbekistan "Inventory and assessment of the vertebrate fauna current conditions of Tashkent region as the basis for biological resources monitoring system creation".

To perform an inventory of the Tashkent region fauna, standard operating procedures were developed [1]. Approaches and methods have been successfully tested and can be used in other regions of the country: 


\subsection{Information collection, storage and analysis}

A database was created for systematization, storage and subsequent analysis of information. The database framework was developed in Excel application, which allows to use it in the ArcGIS program. When filling the database, the available "SAS Planet" and "Google Earth" computer programs were used. The standard two-level list of habitats for the whole of Uzbekistan was developed for the territorial analysis of the species distribution. On its basis, the original map of the habitats of Tashkent region was compiled in the ArcGIS program (Fig. 1). The boundaries of the habitats on this map are fairly accurate and up-todate, as they were determined and corrected based on high-resolution satellite images.

\subsection{Existing information sources}

To fill in the database, the information sources that meet the requirements of reliability and objectivity were used. The "basic level" of the inventory of mammals was made up of scientific publications for more than 100 years of zoological research in Tashkent region 240 publications in total.

A significant amount of departmental information on the biodiversity of the Tashkent region (accounting data of the statistical services, sanitary and epidemiological control, hunting, nature protection profile) was also included in the database and used for analysis.

Zoological collections of the National University of Uzbekistan, the Institute of Zoology of the Academy of Sciences of the Republic of Uzbekistan, the Republican Museum of Nature, as well as private Humerus Collection of O.V. and M.G. Mitropolsky have become an important source of the information.

The above data allowed to analyze the changes in the fauna species composition, the conditions of populations and habitats of species in connection with the anthropogenic transformation of territories.

\subsection{Field research - the gaps closing basic method}

You are free to use colour illustrations for the online version of the proceedings but any print version will be printed in black and white unless special arrangements have been made with the conference organiser. Please check whether or not this is the case. If the print version will be black and white only, you should check your figure captions carefully and remove any reference to colour in the illustration and text. In addition, some colour figures will degrade or suffer loss of information when converted to black and white, and this should be taken into account when preparing them.

Field research were conducted to obtain up-to-date information and clarify controversial issues on the species distribution, abundance conditions, habitats and anthropogenic loads level. Collection of field data was carried out by standard generally accepted methods of intravital study of mammals [2,3]and included: walking route counts of mammals and traces of their vital activities (footprints, droppings, presence of burrows, biting marks, rooting damage); on-sites counts; counts and clarification of species composition with camera traps; bone debris collection, birds of prey pellets in order to determine species identification of the victims. Along with this, the survey method and the questionnaire survey of the local peoples and users of nature resources were used. The assessment of anthropogenic impacts on the mammalian fauna was carried out in accordance with the previously developed methodology [4]. 
Field research in 2018-2020 covered almost all types of habitats of Tashkent region in the altitude range from 275 to $3980 \mathrm{~m}$ above sea level. 65 field trips were made, 271 points were surveyed.

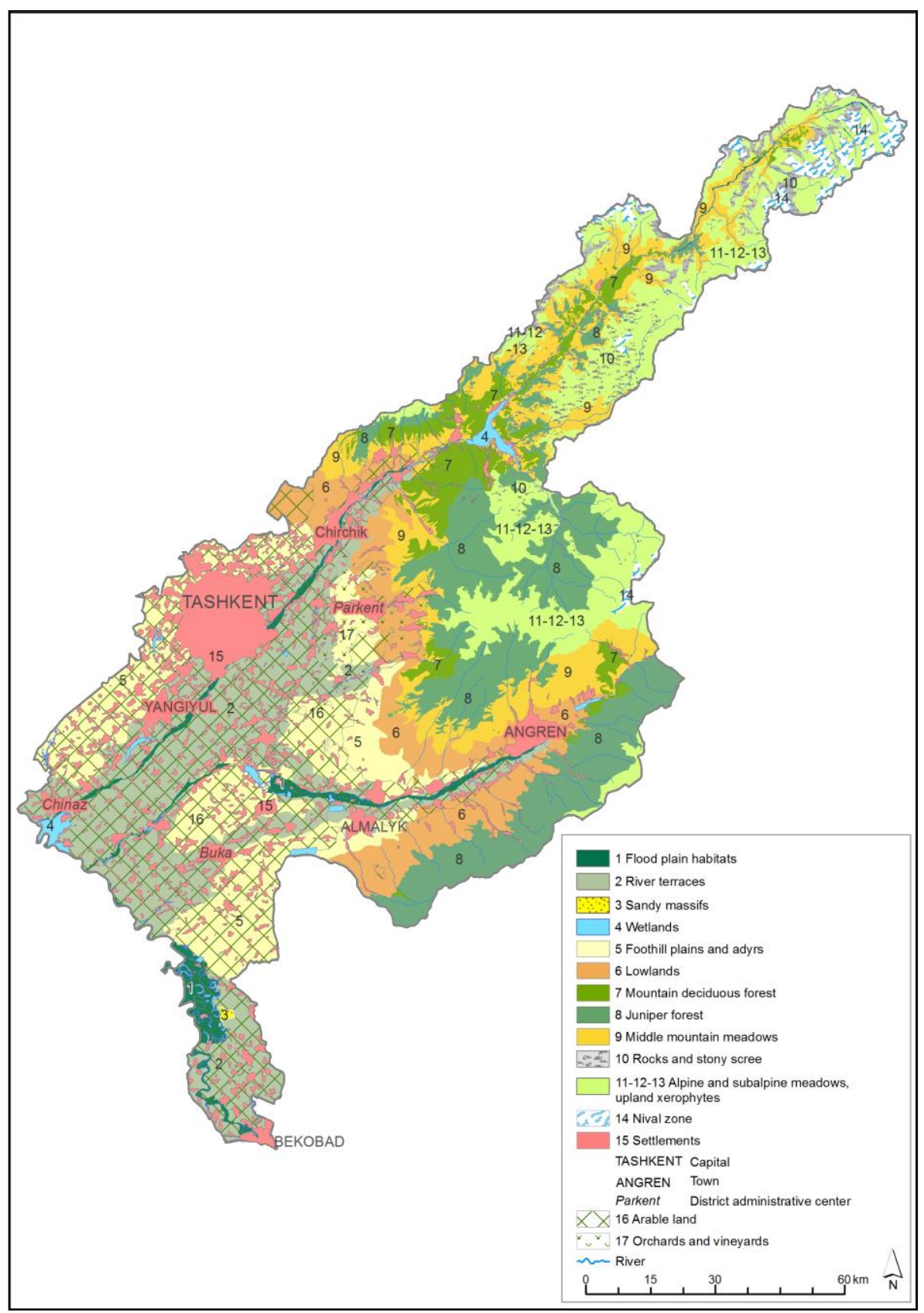

Fig. 1. Map of the main types of habitats of Tashkent region 


\section{Results}

Based on the results of the inventory of Tashkent region, standard species profiles were compiled for 325 species of terrestrial vertebrates - amphibians, reptiles, birds and mammals. For each species, the current species name, conservation status, distribution and residence characteristics, typical habitats, abundance conditions, distribution map, existing threats, economic significance (for economically significant species) or recommended conservation status (for rare species of this territory), recommended conservation or sustainable use measures were provided.

Below we present standard species profiles for 17 species of mammals that have a certain economic significance - they are hunting object; agricultural pests; carriers of feral herd infections.

Tolai Hare Lepus tolai (Pallas, 1778) is widely but sporadically distributed within Tashkent region (Fig. 2). The specific habitats of this species are floodplain plots, foothill plains and adyrs, lowlands, deciduous and juniper mountain forests. The range of altitude distribution is $400-2,300 \mathrm{~m}$ above sea level.

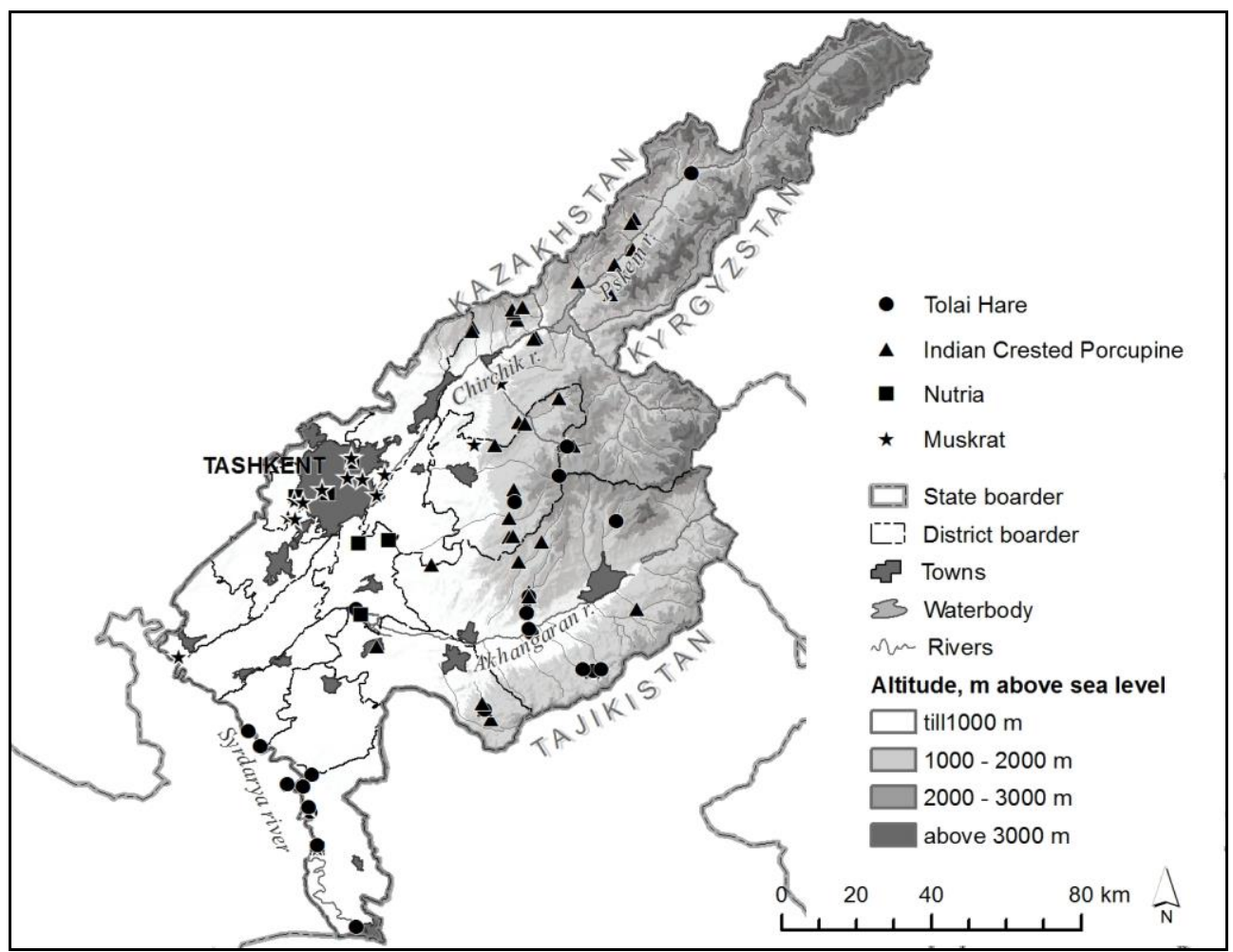

Fig. 2. Distribution of the Tolai Hare, Muskrat, Nutria and Indian Crested in Tashkent region

The hare completely disappears from the areas of foothills and lowlands, which are subjected to intensive agricultural development. In mountainous areas of the region, hare is numerically insignificant and locally distributed. We noted individual findings of the species on the northern slopes of the Kuramin ridge. Modern findings are also known on the Chatkal and Ugam ridges [5]. Hare is rare in the territory of the Chatkal Natural Reserve [6].

In the territory of the region, hare is numerically insignificant. The lowest abundance of the species is noted for mountain habitats. According to the records of 2017-2018, the 
abundance of hares in free lands of the region is about 2,300 individuals, in the territory of hunting farms $-2,000-2,200$ individuals, on the lands of the forest reserves - $300-350$ individuals. The estimated abundance in the region is 5-5.5 thousand individuals.

The primary factors limiting the abundance of the species in the territory of the region are the loss of natural habitats under the impacts of agriculture and grazing, illegal hunting, natural factors (severe winters, epizootic diseases).

Tolai Hare is a hunting species. To ensure sustainable use, the recommended annual quota for hare hunting in the territory of the region shall be no more than 500-550 individuals.

Muskrat Ondatra zibethicus (L. 1766) was acclimatized in Uzbekistan more than 80 years ago. Currently, it is widely distributed in all reservoirs and irrigation canals of the plain part of the region, including in settlements (Fig. 2). Slightly penetrates into the foothills. The range of altitude distribution is $240-900 \mathrm{~m}$ above sea level.

Typical Muskrat habitats are shallow plain water bodies with stable water level and dense coastal vegetation.

The abundance of Muskrats in the region is stable, with a discernible tendency to increase. The expansion of the range is associated with the creation of fish farms, development of irrigation network and other artificial reservoirs, as well as the almost complete absence of hunting [7]. According to our expert assessment, the total abundance of the species within the region is several thousand individuals.

The primary limiting factors are the unstable hydrologic regime during the fields irrigation, which leads to seasonal drying of canals, and the clearing of the banks of irrigation facilities; natural factors - drought, cold winters.

Muskrat is a fur trapping species. The quota for this species hunting in 2018 was 300 pieces, but not a single individual was officially hunted. With an increase in Muskrats abundance, it can cause some harm to the fisheries. Muskrat rooting activity can disrupt the integrity of the banks and dams of hydraulic structures. In this regard, as well as to justify the annual hunting quotas, it is required to conduct abundance counts and determine the actual reserves of the species.

House Mouse Mus musculus (L. 1758) is a synanthropic widespread species typical for anthropogenic and urbanized territories of the region. In the warm seasons of the year, the house mouse is widely distributed in the vicinity of settlements. With onset of cold weather, there are mass migrations of mice to residential premises.

The house mouse is widespread everywhere in the plain part of the region, the lower and middle belt of the mountains (Fig. 3). In mountainous areas, it can be found only in the presence of permanent or temporary human housing. The range of altitude distribution is volatile between $240-2,500 \mathrm{~m}$ above sea level.

In some years, the abundance of house mouse in settlements, agricultural lands of the oasis area and in the foothills can reach high rates - from 8 to $20 \%$ of falling into traps. In the river valleys, the abundance is up to $2 \%$ of falling into traps. Single individuals are recorded in all ecosystems of the region, including the highlands.

The house mouse is a pest of agriculture. It harms the planting of grain crops, food in warehouses, in feed storages on livestock farms. This species is a carrier of dangerous infections for humans. It is required to monitor and control the abundance of the species constantly. 


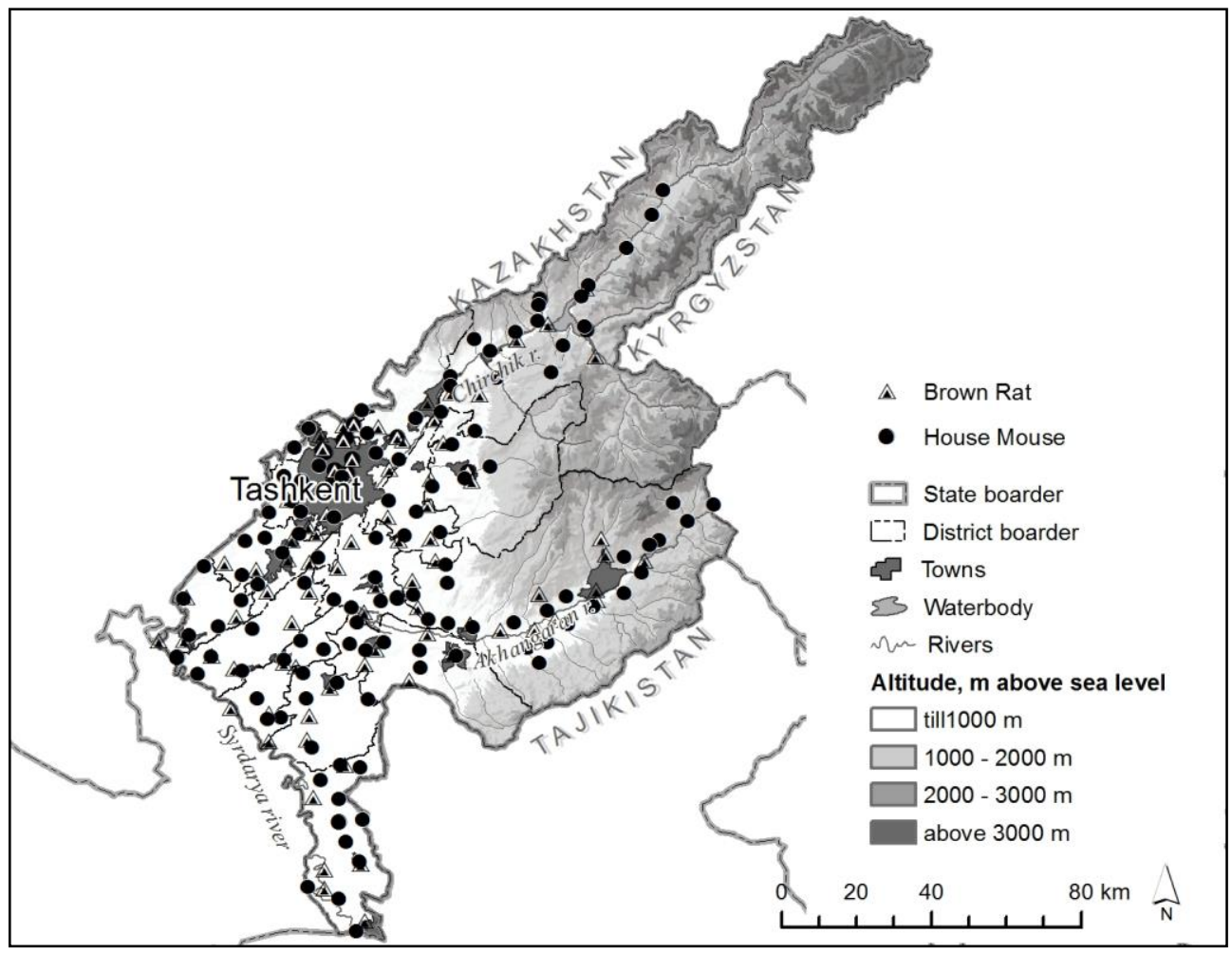

Fig. 3. Distribution of the House Mouse and Brown Rat in Tashkent region

Brown Rat Rattus norvegicus (Berkenhout, 1769) is a typical synanthropic invasive species and actively expands its range. The penetration of the species in Tashkent region occurred in the early 40 s of the 20th century. According to I. I. Kolesnikov's [8] opinion, "wild" populations of this species in the city of Tashkent occurred as a result of multiple escapes of laboratory white rats from vivariums and breeding nurseries. V.P. Promptov [9], on the contrary, argued that the appearance of Brown Rats occurred here as a result of their importation by rail. In our opinion, the penetration of Brown Rat in Tashkent region occurred by rail, and its further spread is associated with the expansion of the railway and irrigation network, the emergence of new settlements and livestock farms. The invasion of the Brown Rat has a significant negative impact on the native fauna of the region. The previously numerous Turkestan Rat Rattus turkestanicus (Satunin 1903) was quickly displaced from the plains to the mountain habitats and completely replaced by a larger and more aggressive Brown Rat. The last individuals of the Turkestan Rat were recorded in Tashkent in 1953 - 7-8 years after the appearance of the Turkestan Rat here [10].

Currently, the species is widely populated throughout the plain part of the region, where its habitats are strictly confined to human settlements (Fig. 3). The Brown Rat does not form independent populations in the wild nature of Uzbekistan. In natural ecosystems, it occurs only occasionally and only in the warm season.

The abundance of Brown Rat in the city of Tashkent ranges from 0.1-0.3 to 1.6-2.5 individuals per $1000 \mathrm{~m}^{2}$. The largest abundance of the species is noted among the singlestorey buildings of the private sector, uncontrolled landfills, along the banks of ditches and canals. It should be noted that the vast amount of food waste in markets, landfills and 
catering enterprises attracts Brown Rats, and their abundance here is an order of magnitude higher than in other territories.

The Brown Rat is a pest of agriculture, destroys and spoils food, industrial goods and stocks of feed for farm animals. This rodent is the cause of biological damage and the natural carrier of more than 20 dangerous infections [10]. To prevent the harmful activity of this alien invasive species, constant abundance control and strict measures to limit it shall be required.

Indian Crested Porcupine Hystrix indica (Kerr, 1792) is widely distributed in Tashkent region in the lower and middle belt of the Western Tian Shan mountains (Fig. 2).

The specific habitats of porcupine - foothills, lowland plots of the rivers of the lower mountain belt, the belt of woody and shrubby vegetation of the lowlands - are located in the altitude range from 400 to $2,000 \mathrm{~m}$ above sea level.

The abundance of the species in the territory of the region is naturally low, without sharp fluctuations, relatively stable. According to the records of 2015-2017, the total abundance on the territory of hunting farms is, on the average, 400, in 2019 - about 600 individuals. According to the records of 2016-2017, in the forest hunting farm "Shavazsay" the abundance was 400 - 440 individuals. Taking into account the area of suitable habitats, the total abundance of the species in the region can be estimated at $700-900$ individuals.

The primary limiting factors for the species are illegal hunting, degradation of natural foothill and lowland habitats under the influence of economic development.

The porcupine is the hunting species. It causes minor damage to tree plantations, gnawing and eating the bark of young plants, and melons. To ensure the sustainable use of this species, the recommended annual quota for the region may be $70-90$ individuals.

Coypu Mycastor coypus (Molina, 1782) is the acclimatized species for which semi-free breeding is practiced in Uzbekistan. In nature, it is found near breeding areas on reservoirs with dense reed thickets. The species lives in the reservoirs of almost all hunting farms in the region. Currently, Coypu is regularly observed on irrigation canals and rivers, including within the territory of Tashkent (Fig. 2). The range of altitude distribution of the species in the region is $240-800 \mathrm{~m}$ above sea level.

The Coypu abundance conditions in Tashkent region are estimated as consistently low. Sporadic findings are noted in various plain areas of the region and on the canals of Tashkent. Probably, the increase in average temperatures in the winter months over the past 10 years has contributed to the stabilization of the abundance and some expansion of the range of the species. The total abundance of the species within the region is $300-400$ individuals. The primary factor limiting the abundance and distribution of Coypu is the freezing of water bodies in cold winters.

Coypu is a breeding subject on fur farms. Feral individuals are the hunting species. This species is also a carrier of pathogens of several forms of leptospirosis and other dangerous infections. Work to determine the current conditions and trends in the distribution of this valuable fur-bearing animal in the territory of the region and to arrange its sustainable use is required.

Red Fox Vulpes vulpes (L. 1758) is an ecologically plastic widespread species in the region. It lives in all types of landscapes of Tashkent region - from floodplain ecosystems to highlands (Fig. 4). It also inhabits the outskirts of cities and towns. The range of altitude distribution of the species is $260-2,800 \mathrm{~m}$ above sea level.

According to the records of 2017-2019, the abundance of the species in the territory of hunting farms in the region is from 365 to 510 individuals. In 2017, 250 individuals were registered in the free lands. In 2015-2017, on the lands of the forest reserves, the abundance 
was estimated at 100 individuals. According to expert estimates, the total abundance of the species in Tashkent region is at least 3,000 - 3,500 individuals.

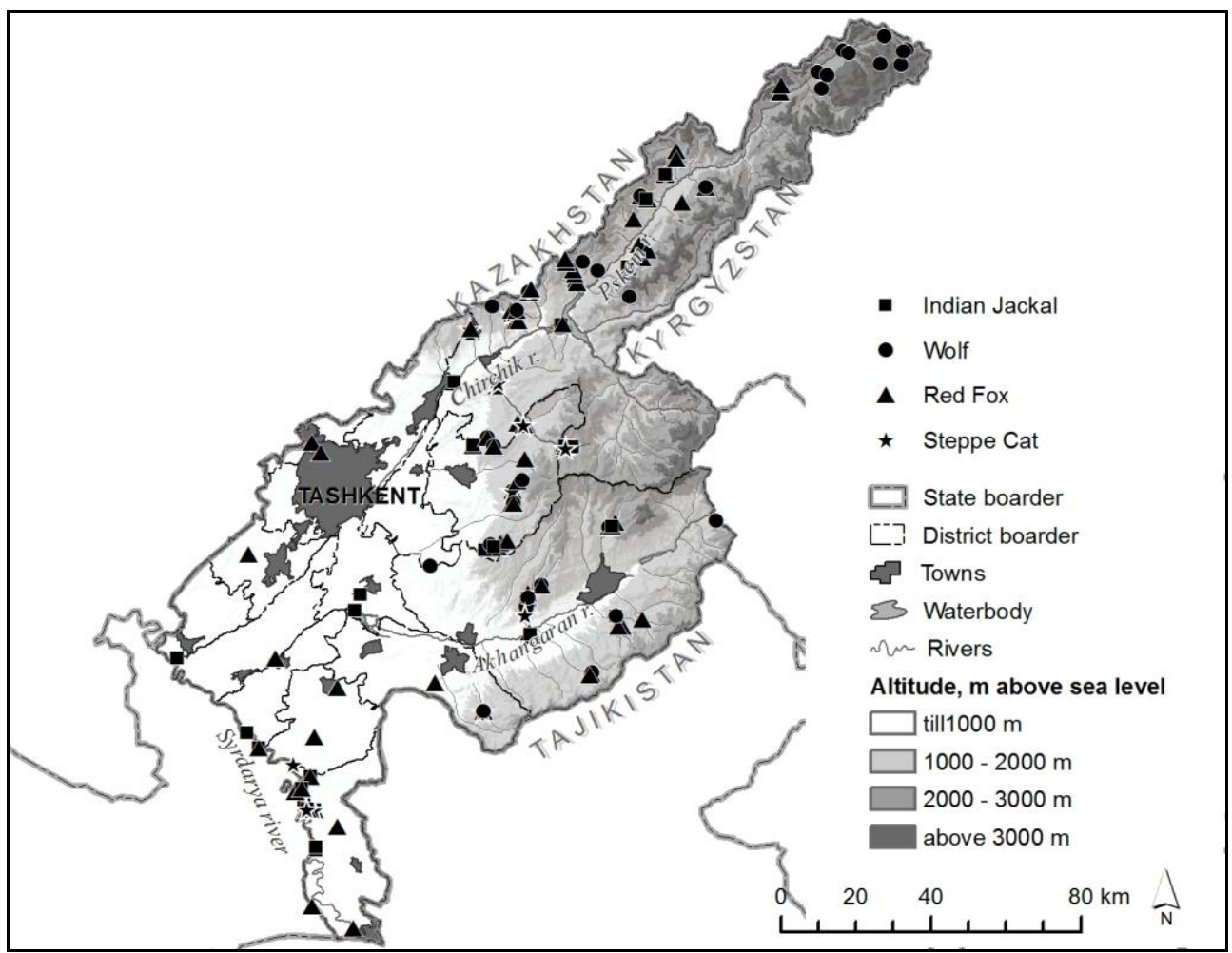

Fig. 4. Distribution of the Red Fox, Indian Jackal, Wolf and Steppe Cat in Tashkent region

The primary limiting factor is the reduction of food potential. Anthropogenic transformation of habitats does not lead to the extinction of the species, but significantly reduces the abundance of Red Foxes, which is associated with the deterioration of feeding and protective conditions.

The Red Fox is a hunting species, the recommended annual quota for its hunting can be about 300 - 400 individuals. The Red Fox is also a natural carrier of rabies and a number of other dangerous infections, and needs sanitary and epidemiological control.

Indian Jackal Canis aureus (L. 1758) was rare in the valleys of the Chirchik and Angren rivers until the middle of the 20th century [11]. The expansion of irrigation network and concomitant increase in the area of coastal shrubs and reeds in subsequent years became a favorable factor for the expansion of the species range within Chirchik-Angren interstream [12]. At present - it is a common, widespread species of river valleys in the plain part of the region. In floodplain habitats, Indian Jackal penetrates into the lower and middle belts of the Western Tian Shan mountains to the same altitudes as the floodplain vegetation (Fig. 4). The limiting factor here is the spread of a larger species - wolf.

In recent decades, Indian Jackal has adapted well to the living in agricultural land, expanded its range and significantly increased its abundance. According to the records in 2015-2017 in the territory of hunting farms of the region, the abundance of species was 1,300 - 1,350 individuals, in free lands there were from 727 to 1,066 individuals. In 20162017 , on the lands of the forest reserves, the abundance was $280-350$ individuals. In general, for Tashkent region, the abundance is estimated at 2,500 - 3,000 individuals. 
Indian Jackal is a fur trapping species. It harms the hunting economy, and in case of high abundance harms livestock also. Taking into account the ecological characteristics of the species, the recommended annual quota for Tashkent region is $500-700$ individuals. The species is a natural carrier of rabies and needs sanitary and epidemiological control.

Wolf Canis lupus (L. 1758) was previously widespread distributed in the territory of Tashkent region. By the middle of the 20th century, due to the intensive economic development of the plain part, the species disappeared from the floodplains of rivers and the marginal parts of oases (Fig. 4). Currently, it is found mainly in the mountains in all altitude areas (from 900 to $3,300 \mathrm{~m}$ above sea level), where it reaches a density of 2-3 individuals per $100 \mathrm{~km}^{2}$. The development of distant-pasture livestock breeding in mountainous territories improves the predator's food potential [12].

According to the records of 2015-2017, in the territory of hunting farms of the region, the abundance of wolves is estimated at 120 individuals, in 2019 - at 170 individuals. In the forest hunting farm "Shavazsay" the wolf abundance in 2016-2017 was 10-12 individuals. Data concerning the wolf abundance on the lands of the forest reserves of the region are not available. According to expert estimates, the current abundance of wolves within the region is 300 - 350 individuals.

The primary limiting factor for the species is the loss of natural habitats under the influence of agriculture in plain and foothill areas, the food potential conditions.

The wolf is the hunting species, but it is hunted in small quantities. It causes damage to livestock. The wolf causes significant damage to the livestock of hunting species in the mountains - wild boar and roe deer [13]. The recommended annual quota for wolf hunting in the territory of Tashkent region is $30-35$ individuals. The species is a natural carrier of rabies and needs sanitary and epidemiological control.

Stone Marten Martes foina (Erxleben, 1777) is a typical inhabitant of a highstanding juniper forest among outcrops of rocks and stony scree. It penetrates into the Alpine belt, where it is found in the settlements of Menzbier's marmot Marmota menzbieri [14]. Within Tashkent region, it is observed in the middle altitude and high-altitude mountains of the Pskem, Chatkal ranges, the Karzhantau ridge, on the northern slopes of the Kuramin ridge (Fig. 5) in the altitude range from 1,200 to 3,800 m above sea level.

The abundance of Stone Marten within the region is consistently low. According to the records in the valley of the Pskem River, the maximum density is 3 individuals per $10 \mathrm{~km}^{2}$. The total abundance of the species within the region can be estimated at $800-1,000$ individuals. The basic habitats of the Stone Marten in the mountains are practically not exposed to anthropogenic influences, which contributes to the stable abundance conditions of the species.

The distribution over the territory and the species abundance are closely related to the food potential conditions - the abundance of rodents. The illegal hunting also has a negative impact on the species.

The Stone Marten is a hunting species in Uzbekistan. However, at present, planned and justified hunting is not arranged, the species is hunted only by poachers.

Weasel Mustela nivalis (L. 1766) is an ecologically plastic species, well adapted to anthropogenic environmental changes. It inhabits almost all the territories of the region from agricultural land and urbanized landscapes to the upper belt of the mountains (Fig. 5), where it is associated with the settlements of Tian Shan Souslik [15]. It also lives in the vicinity of human habitation. 


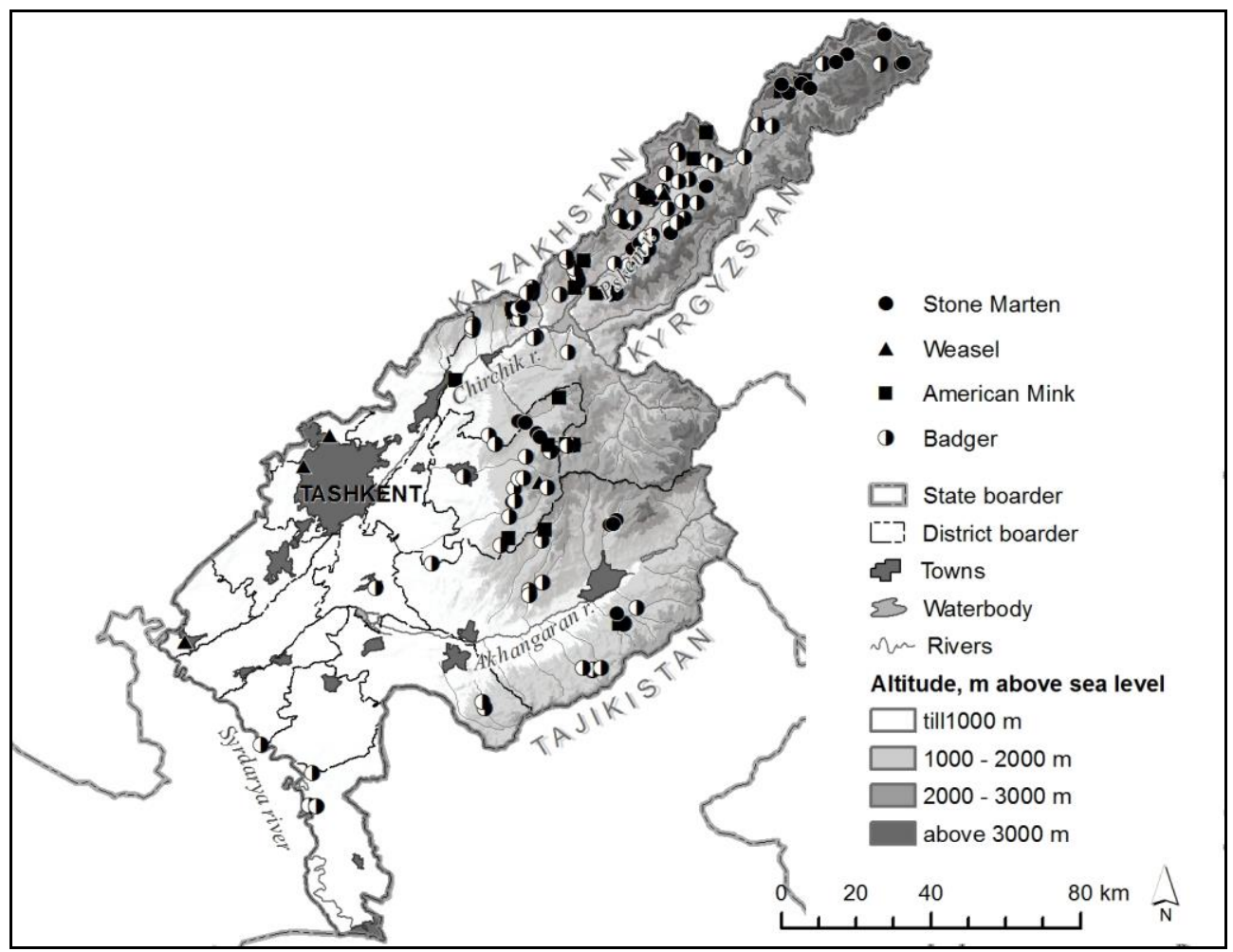

Fig. 5. Distribution of the Stone Marten, Weasel, American Mink and Badger in Tashkent region

In general, the weasel abundance is naturally low, but in some places the species can be numerous. According to our observations, the occurrence of weasels in the mountains can be from 3 to 5 individuals per $1 \mathrm{~km}$ of the route. The distribution over the territory and the weasel abundance conditions are closely related to the presence of food items - rodents.

Its wide distribution, ecological plasticity and stable abundance make it possible to classify the weasel as a hunting species. The weasel can also cause damage to the poultry industry.

American Mink Neovison vison (Schreber, 1777) - is spontaneously introduced species. In the early 70 s of the last century, several dozen animals escaped from the Bostanlyk mink farm to the valley of the Chirchik river. Our studies confirm that the expansion of the species in the basins of the Chirchik and Angren rivers is quite intense. This is facilitated by favorable natural conditions and a free ecological niche in the mountain rivers valleys, which the American Mink has successfully occupied.

At present, the range of the species in Tashkent region covers the river valleys of the Chirchik and Akhangaran river basins from the plain to the mid-mountain part of the southeastern slopes of the Karzhantau, Ugam, Pskem, and Eastern part of Chatkal ridges (Fig. 5). The most favorable for the habitat of the species are bottomland plots where there are fish stocks, and the banks have a sufficient number of natural shelters (rocky debris, gullies under the roots of trees, etc.). The range of altitude distribution of the species is $520-2,900$ $\mathrm{m}$ above sea level.

According to our data, the abundance of American Mink within the region can be from 1 to $3-3.5$ individuals per $1 \mathrm{~km}$ of the coastline of the rivers suitable for the habitat of the species. We estimate the total abundance of the species in the territory of the region as not less than 3,000 - 3,500 individuals. 
Anthropogenic activities do not have a significant negative impact on the species conditions. The primary factor limiting the abundance of American Mink are the food potential conditions.

The American Mink in Uzbekistan is a hunting species. However, applications for the hunting of this species from hunting entities were practically not received. The recommended annual quota for Tashkent region may be 350 or more individuals. In some areas, mink can cause significant damage to the fish stocks conditions and native ornithofauna. It is required to manage the abundance of the species in protected natural areas, in hunting and fishing farms.

Badger Meles meles (L. 1758) within the region is distributed in almost all abandoned lands and thickets along the canals of the irrigation network and reservoirs of the plain part of the region (Fig. 5). It rises to the upper border of the juniper forest up to the altitudes of 2,500 - 2,700 $\mathrm{m}$ above sea level.

The badger is especially typical and numerous in the belt of tree and shrub vegetation of the middle altitude mountains. According to our observations, it is common, sometimes numerous in all low-hill terrains and middle altitude mountains of the Chirchik and Angren river basins.

The abundance of the species is subject to significant fluctuations. Under favorable habitat conditions, the density can reach 5 individuals per $1 \mathrm{~km}^{2}$. In 2015-2017, the abundance in the territory of the hunting farms of the region ranged from 168 to 392 individuals. In 2019, the abundance of the species in the territories of hunting farms and in free lands was 840 individuals. On the lands of the forest fund in 2016, only 22 individuals were counted, in $2017-32$. The total abundance of the species within the region can be estimated at 1,500 - 1,700 individuals, in favorable years - up to 4,000.

The primary limiting factors for the species are cuttings down of tree and shrub vegetation in their habitats, illegal hunting, and natural factors (epizootic diseases). The species responds positively to a number of anthropogenic factors - the expansion of the irrigation network, the area of gardens and melon crops.

The badger is a hunting species. Its fat is used in folk medicine. The recommended annual quota for the region may be 150-170 individuals.

Steppe Cat Felis silvestris ornata (Gray, 1832) is a widespread species. It inhabits floodplain habitats, wetlands, sub-mountain plains and foothills, lowlands, and is found in the middle altitude mountains. It prefers habitats with discernible woody and shrubby vegetation in the altitude range from 240 to $2,200 \mathrm{~m}$ above sea level. It is not found on developed lands (Fig. 4).

The abundance of the species in the region is naturally low, relatively stable. In 2017 , 48 individuals were registered on the lands of the forest reserves. Due to the secretive lifestyle of the species, there is almost no modern data on the abundance.

Degradation, fragmentation, and loss of natural habitats due to agriculture and grazing significantly limit the species abundance.

The steppe wild cat is a hunting species in Uzbekistan, but is officially hunting in small quantities. It can cause harm to poultry farming; in hunting farms it destroys pheasant nests.

Wild Boar Sus scrofa (L. 1758) in the plain part of the region is currently preserved only in certain areas of riverside tugai within hunting farms and protected natural areas. In woody and shrubby habitats of the middle belt of mountains, the species is distributed sufficiently widely. In summer, it rises above the border of the mountain forest, in the subalpine belt to an altitude of 3,200 m above sea level. The most typical habitats of the wild boar are floodplain tugai forest and reed thickets, mountain juniper forest (Fig. 6). 
The highest abundance of the species within the region is observed in hunting farms. In 2015-2017, about 710 individuals were registered in the territory of hunting farms of the region. In 2017, 104 individuals were registered on the lands of the forest reserves of the region. Thus, taking into account the suitable habitats conditions, the total abundance of the species within the region can be estimated at 1,000 - 1,200 individuals.

The primary limiting factor for the species within the region is the reduction of the area of tugai and mountain forests under the influence of economic development, grazing, illegal hunting, natural factors (cold winters with high snow cover, predators). The expansion of the irrigation network, drainage canals and sewage lakes creates favorable conditions for the settlement of wild boar.

Wild boar is a hunting species. In previous years, it was annually hunting in a significant amount - up to 350 individuals per year and more [16]. Based on the current conditions of the species in the region, the sustainable use of the species allows to recommend an annual quota for hunting within the range of $100-120$ individuals.

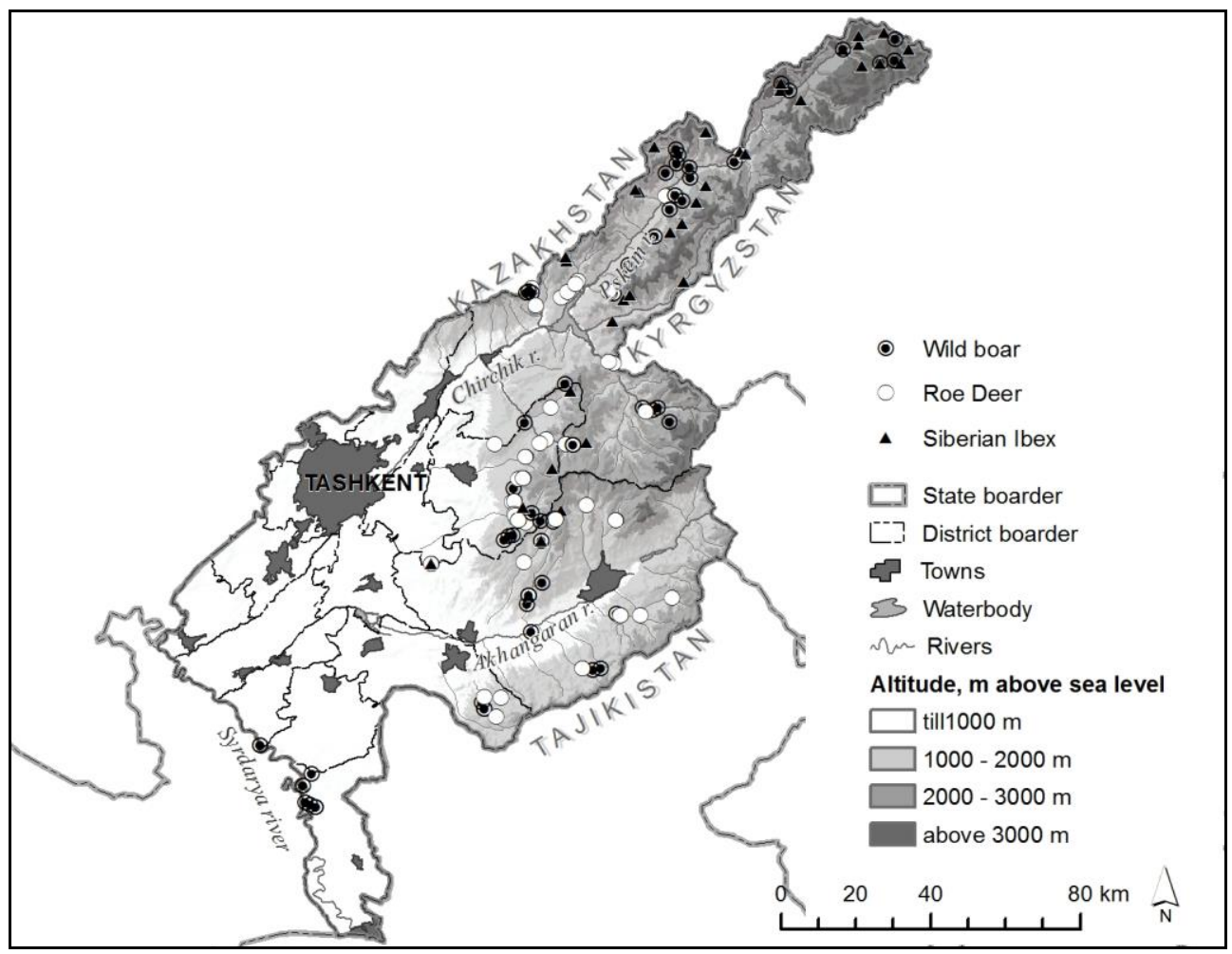

Fig. 6. Distribution of the Wild Boar, Roe Deer and Siberian Ibex in Tashkent region

Siberian Roe Deer Capreolus pygargus (Pallas, 1771) lives within Tashkent region in the Western Tien Shan - in the mountain deciduous forests of the Ugam, Pskem, Chatkal, Kuramin ridges and Karzhantau (Fig. 6) in the range of altitude distribution from 800 to $1,800 \mathrm{~m}$ above sea level. Here is the border of the species range.

The abundance of the species everywhere is low, relatively stable, and can vary over the years, which is associated with the death of animals in snowy winters. In 2015-2017, in the territory of the Beldersay and Kuramin hunting farms, the abundance of the species was 160 individuals averaged. In 2016-2017, in the forest hunting farm "Shavazsay" up to 350 
individuals were registered. According to expert estimates, the total abundance of the species in the region is about $500-550$ individuals.

The primary limiting factors for the species are the cutting down of woody vegetation and overgrazing, illegal hunting. Natural factors are death from predators, especially in winter.

The Roe Deer is a hunting species. The low, but generally stable abundance of the species allows limited licensed hunting. Based on the accounting data, the recommended annual quota for the region can be no more than 25 - 30 individuals. For the purpose of sustainable use of the species, it is required to provide winter feeding of ungulates and control the abundance of wolves [13].

Siberian Ibex Capra sibirica (Pallas, 1776) is a typical representative of the highaltitude communities of the Western Tian Shan. Within Tashkent region, it is found on the Ugam, Maydantal, Pskem, Chatkal, and Kuramin ridges (Fig. 6). The typical habitats of the species are rocky areas, steep slopes and stony scree in the altitude range from 1,600 to $3,600 \mathrm{~m}$ above sea level. In winter and early spring, goats are concentrated in the lower belt of the mountains, in habitats with outcrops of bedrock. In the summer, the ungulates stay in the subalpine and alpine areas, moving in small herds from one mountain valley to another.

The abundance of mountain goats within the region is generally stable. Occasionally, there is a decrease in abundance as a result of epizootic diseases. In some areas, the species is quite numerous. According to our data, the amount of winter groups on the Pskem ridge can reach up to 100 heads, averaging 30 - 50 individuals. The current abundance of goats in the Pskem river basin is estimated at about 250-300 individuals. In 2015-2017, the abundance of mountain goats in the territory of the hunting farms of the region was 210 individuals, in 2016-2017, 320 individuals were registered in the forest hunting farm "Shavazsay". Up to 300 individuals live in the territory of the Chatkal Biosphere Reserve. According to expert estimates, the total abundance of the species, taking into account suitable habitats in Tashkent region, is 1,200-1,300 individuals.

The primary factors limiting the abundance of the species within the region are the degradation of mountain pastures under the influence of grazing, illegal hunting, and natural epizootic diseases.

The mountain goat is a hunting species. The recommended annual quota for the region can be about 150 individuals.

\section{Discussion}

According to the results of the inventory, 68 species of mammals were registered in the territory of Tashkent region, which is $63.5 \%$ of the total diversity of the theriofauna of Uzbekistan. The fauna of economically significant mammals of Tashkent region is represented by 17 species ( $25 \%$ of the species diversity of the theriofauna of the region). Of which, 1 of the two species living in the region belongs to the Lagomorphs, 5 species belong to Rodents (19.2\% of the species diversity of the order within the region), 8 species belong to Carnivores (44.4\%), 3 species belong to Even-Toed Ungulates.

The list of hunting species in Uzbekistan includes the Long-tailed Marmot Marmota caudata (Geoffroy 1844). According to the results of the inventory, this species was estimated by us for Tashkent region as a small number, locally distributed only in the upper part of the Pskem river basin, where the north-eastern border of its distribution passes. The total area of scattered settlements here is about 9,000 hectares, the density is from 0.2 to 5 individuals per hectare. The estimated abundance of the species in the region does not exceed 4,000 individuals. Based on this, the Long-tailed Marmot is not included in our list of economically significant species. On the contrary, a complete ban on its hunting, 
protection of existing settlements, and control over the species conditions and its habitats are recommended.

The situation is similar with two other species living in the territory of Tashkent region. Inhabitants of the foothill plains and adyrs - Corsac Fox Vulpes corsac (L. 1768) and Steppe Polecat Mustela eversmanii (Lesson 1827), were previously the fur trapping species in Uzbekistan [17, 18]. Currently, due to the almost complete economic development of their habitats, these species are in a threatened condition and are included in the latest edition of the Red Book of the Republic of Uzbekistan [19, 20]. In the territory of Tashkent region, Corsac Fox and Steppe Polecat have been preserved only in isolated sites and are on the verge of extinction.

15 species from the list of economically significant are traditional hunting species. However, currently, for a number of reasons 7 of them are hunted in small quantities or not hunted at all. This problem requires close attention, as it leads to underutilization of existing biological resources.

Two economically significant species - the House Mouse and the Brown Rat, combine two serious negative effects on humans - they are pests of agriculture and, at the same time, carriers of natural focal infections that are dangerous for humans.

4 economically significant species of mammals of the region are alien to the fauna of the country as a whole. The introduction of the American Mink, Muskrat and Coypu occurred as a result of the targeted importation of these species to Uzbekistan for breeding. The Brown Rat entered the territory of Uzbekistan and, in particular, Tashkent region, independently, during the process of economic development. The American Mink, Muskrat and Coypu have occupied free ecological niches and as a result do not have a negative impact on the native fauna. The widespread dispersal of the Brown Rat led to a reduction in the range and the displacement of the native Turkestan Rat from plain habitats to the mountains.

The hunting resources of the theriofauna of Tashkent region are mainly concentrated on the lands of the forest reserves and hunting farms. The basic habitats of hunting species are mountain, floodplain and wetland areas.

The results of our research have shown that not all hunting species are equally affected by negative factors. The greatest anthropogenic pressure is experienced by the inhabitants of the plains due to the reduction, degradation and/or fragmentation of lands under the influence of economic development. This is confirmed by the situation described above with the Steppe Polecat and the Corsac Fox.

The analysis of the influence of the basic types of impacts on the conditions of hunting mammal species in Tashkent region showed that the degradation, fragmentation and reduction of the areas of typical habitats in 9 of them occurs under the influence of agriculture. The condition of 6 species is significantly affected by grazing. One of the basic reasons for the abundance reduction of 7 species is illegal hunting or poaching.

Almost all hunting species living in the lowlands and middle altitude mountains suffer greatly from the impact of recreational loads on their habitats - these territories are mainly used by the peoples for mass recreation.

To a relatively lesser extent, the middle and upper mountain belts are subject to economic impact. Accordingly, the stenobiont species that live here, such as the Siberian Ibex and the Stone Marten, experience a limited set of anthropogenic threats - grazing and poaching.

Ecologically plastic species, such as Indian Jackal, Red Fox, Weasel, Badger, Wild Boar, are more successful than others in adapting to anthropogenic changes in the environment. The development of the irrigation network creates favorable conditions for their existence. 
Almost all economically significant species are more or less affected by various natural factors. At the same time, the most "protected" species are those with a tendency to synanthropization.

The results of the analysis of negative impacts are the required information on the basis of which applied measures for the sustainable use of biological resources are developed.

For the sustainable use of the fauna of economically significant mammal species of Tashkent region, the following is required:

-annual number counts;

-the maintenance of the state cadastre;

- regular implementation of biotechnical activities in the territories of forestry and hunting farms;

-improving the effectiveness of territorial protection to prevent cases of illegal hunting, conservation and restoration of natural habitats of species.

\section{References}

1. R.D. Kashkarov, Yu.O. Mitropolskaya, M.A. Gritsina, A.G. Ten, T.V.Abduraupov, EJPBS 6.10, 56-61 (2019).

2. A.H. Formozov, Zool. J. XI. 2, 32-37 (1932)

3. A.F. Kovshar, P.F. Yanushko, Proceedings of the Aksu-Jabagly State Nature Reserve 2, 203-236 (1965)

4. Yu.O. Mitropolskaya, Assessment of anthropogenic impacts on mammalian fauna to develop measures for their conservation and sustainable use. Methodological Recommendations. (Tashkent, Acad of Sc. Pr. H., 2017. 37 p)

5. O.V. Mitropolskiy, Biodiversity of the Western Tien Shan: Materials for the Study of Birds and Mammals in the Chirchik and Ahangaran River Basins (Uzbekistan, Kazakhstan) (Tashkent-Bishkek, 2005. 166 p)

6. D.E. Golovtsov, Proceedings of the Chatkal State Nature Reserve 4, 178-220 (2007)

7. Yu.O. Mitropolskaya, Zoological Science of Uzbekistan: Current Problems and Prospects of Development. Proceedings of the Republican Scientific and Practical Conference, 248-254 (2020)

8. I.I. Kolesnikov, Proceedings of the Central Asian University. Biol. Sc. 32.2, 18-25 (1952)

9. V.P. Promptov, Uzb. biol. J. III, 66-69 (1962)

10. O.V. Mitropolskiy, A.S. Nematov, J.A. Azimov, A.O. Yuldashev, Uzb. biol. J. VII, 74-81 (2007)

11. G.I. Ishunin, Fauna of Uzbek SSR, III (Tashkent, 1961. 273 p)

12. R.D. Kashkarov, Selevinia 1-4, 150-158 (2002)

13. B.I. Dyakin, Biodiversity of the Western Tien Shan: Protection and Sustainable Use, 93-97 (2002)

14. V.I. Mashkin, A.L. Baturin, Menzbier's Marmot (Kirov,1993. 143 p)

15. D.F. Jeleznyakov, I.I. Kolesnikov, Proceedings of the Mountain-forest State Nature Reserve 1, 110-112 (1958)

16. A.V. Esipov, Cadastral Guide to Hunting and Fishing Animals of Uzbekistan, 63 (Tashkent: FAN, 1992.) 
17. A. Zakirov, Cadastral Guide to Hunting and Fishing Animals of Uzbekistan, 58 (Tashkent: FAN, 1992)

18. R.A. Urmanov, Cadastral Guide to Hunting and Fishing Animals of Uzbekistan, 62 (Tashkent: FAN, 1992)

19. Yu.O. Mitropolskaya, The Red Book of the Republic of Uzbekistan, 306-307 (Tashkent, Chinor ENK, 2019)

20. Yu.O. Mitropolskaya, R.D. Kashkarov, The Red Book of the Republic of Uzbekistan, 310-311 (Tashkent, Chinor ENK, 2019) 